\title{
Assessment of awareness of human papillomavirus infection impact on oral cavity among patients
}

\author{
Justyna Oleszkiewicz-Śpiołek ${ }^{1}$, Paulina Adamska ${ }^{1}$, Giulia Marvaso ${ }^{2,3}$, Barbara A. Jereczek-Fossa ${ }^{2,3}$, Piotr Wychowański \\ Anna Starzyńska ${ }^{1}$
}

1Department of Oral Surgery, Medical University of Gdansk, Gdansk, Poland ${ }^{2}$ Division of Radiotherapy, IEO European Institute of Oncology, IRCCS, Milan, Italy ${ }^{3}$ Department of Oncology and Hemato-oncology, University of Milan, Milan, Italy ${ }^{4}$ Department of Oral Surgery, Medical University of Warsaw, Warsaw, Poland

\begin{abstract}
Introduction: Human papillomavirus (HPV) is responsible for oral cavity lesions such as squamous papilloma, multiform epithelial hyperplasia, condylomata acuminata, giant cell fibroids or squamous cell carcinoma.

Aim: To assess the patients' awareness of HPV infection's impact on oral health.

Material and methods: This was a prospective study of dental patients who were treated in the Department of Oral Surgery at the Medical University of Gdańsk (Gdańsk, Poland) from January to February 2019. Inclusion criteria were as follows: Polish-speaking patients over 18 years old. Exclusion criteria were as follows: people with limited Polish language knowledge and under 18 years old. Participation was voluntary based on the written consent. Descriptive and bivariate statistics were computed and the $p$-value was set at $\leq 0.05$.

Results: Three hundred and sixty-three people (58.13\%: females; 41.87\%: males; mean age 21 years, range: 18-65) were included in the study. Women were more aware what HPV was $(p=0.011)$, the fact that HPV infection could be latent $(p=0.018)$, responsible for the oral cancer $(p=0.032)$, there was an HPV vaccine $(p<0.001)$, and how to prevent infection $(p<0.001)$; relationship between age and the fact that HPV infection may be responsible for the oral cancer ( $p=0.007)$, HPV infection methods ( $p<0.001$ ), characteristics of the lesions caused by the HPV on the mucous membrane $(p<0.001)$, and how to prevent infection $(p=0.044)$.

Conclusions: Our study suggests that patients' awareness of the influence of HPV infections on oral health is limited. Therefore, more attention should be paid to the education of the patients and to prevention programs.
\end{abstract}

Key words: Human papillomavirus, HPV, squamous cell carcinoma.

\section{Introduction}

Human papillomavirus (HPV) is a virus from the papilIomoviridae group of DNA viruses. There are as many as 150 types of this virus and we can divide them into two groups based on cancer risk: low-risk human papillomavirus (LR HPV) and high-risk human papillomavirus (HR HPV) [1-3]. HPV LR serotypes with a low oncogenic risk are most often associated with benign lesions on mucous and cutaneous membranes e.g. leukoplakia, erythroplakia, erythroleukoplakia, Lewandowsky-Lutz dysplasia (Epidermodysplasia verruciformis, EV), focal epithelial hyperplasia, condylomata acuminata or warts (cutaneous, mucous membranes). The following HPV LR types are responsible for these lesions: 1, 2, 3, 4, 6, 7, 10,
$11,13,16,18,30,31,32,33,34,35,40,42,43,44,45,52$, $53,54,55,57,59,61,62,64,66,68,69,71,72,73,81,83$, 84,89 and 120 [4-7]. Whereas HPV HR serotypes with a high oncogenic risk include HPV 2, 3, 6, 11, 13, 16, 18, 26, $31,32,33,35,39,45,51,52,53,56,57,58,59,6667,68$, $69,70,73$ and 82 . HPV high-risk types 16 and 18 are the most common aetiological factors of oral squamous cell carcinoma. Serotypes HPV 16 are responsible in 66-82\% and HPV 18 in $26-34 \%$ for the presence of HPV-positive oral cancer $[5,8,9]$.

The main aetiological factors of head and neck cancer, including oral cancer, are smoking and alcohol consumption. Tobacco-dependent oral cancer mainly affects people over 50 years of age. A worrying trend is increas-

Address for correspondence: Anna Starzyńska, Department of Oral Surgery, Medical University of Gdańsk, 7 Debinki St, 80-211 Gdansk, Poland, phone: +48 5834915 71, e-mail: ast@gumed.edu.pl

Received: 13.05 .2020 , accepted: 16.06 .2020$. 
ing occurrence of behaviours in younger age groups. In this population, the presence of HPV infection with serotypes 16 and 18 is more frequent. They are also responsible for the occurrence of cervical cancer in females [10]. During chronic HPV infection, the risk of cervical cancer increases almost 500 times. The presence of HPV infection is necessary for the development of cancer, however not every patient with HPV develops cancer [11]. The frequency of HPV infection is higher in males than in females [12]. The infection may occur due to early sexual initiation, large number of sexual partners, poor hygiene or via shared underwear or towels. People at risk of HPV infection are females using oral hormonal contraception, and those who are immunocompromised and poorly nourished. Some sexual behaviours, including oral sex, are closely related to the HPV transmission from the oral cavity and the genitals. Oral HPV infection is less frequent than genital HPV $[7,13]$. Immunodeficiency (e.g. due to HIV infection) or smoking are associated with an increased risk of oral infection. Persistent HPV infection plays a key role in the development of HPV-dependent diseases [14].

Differentiation of oral squamous cell carcinoma associated with HPV infection is clinically relevant because there is a different response to treatment. This is the subject of an ongoing debate as it has been shown that the treatment of oral cancer associated with HR serotypes and localized in the oral part of the throat or root of the tongue has a better clinical prognosis $[15,16]$. There are many studies on the presence of HPV and its effect on the development of oral cancer. Conducting education and prevention of HPV infection is aimed at increasing awareness among patients, which may result in earlier detection of the disease [4, 17-20].

\section{Aim}

The purpose of the study was to assess patients' awareness of the impact of HPV infection on oral health.

\section{Material and methods}

This was a prospective study of dental patients who were treated in the Department of Oral Surgery at the Medical University of Gdańsk (Gdansk, Poland) from January to February 2019. Patients reported for mandibular third molar odontectomy.

Inclusion criteria were as follows: Polish-speaking patients over 18 years old. Exclusion criteria were as follows: people with limited Polish language knowledge and under 18 years old. Participation was voluntary. Full anonymity was maintained. Written consent was obtained from all participants. Completion of the questionnaire took about 15 min.

The questionnaire form consisted of four sociodemographic questions and thirteen HPV-specific questions.
The questionnaire was an original idea and was prepared on the basis of available literature [1-5, 21]. This group of questions contained 5 single-answer questions and 8 multiple-answer questions (Appendix 1). In the multiple-answer questions, a minimum of three responses were correct. The questions focused on HPV-related terminology, the routes of transmission, mucosal symptoms, lesions in the oral cavity, and methods of treatment. Respondents were asked to answer questions about risk factors for infection, the existence of a vaccine, how to prevent infections, and other diseases that may arise from the presence of HPV. The obtained results were examined in terms of the relationship between the age, sex and education of the respondents and the awareness of the impact of HPV infection on oral health. The respondents were divided into three groups based on age: up to 25 years old (group 1), from 26 to 40 (group 2) and above 41 years of age (group 3 ).

The research project was approved by the Independent Bioethics Committee for Scientific Research at the Gdansk Medical University (NKBBN/441/2019). All participants were informed about the use of their data for research purposes.

\section{Statistical analysis}

The obtained results were analysed statistically using the Statistica v. 13.3 software (StatSoft Inc. Tulsa, USA). Normal distribution was verified using the W. ShapiroWilk test. Comparisons between study groups were compared using a non-parametric test for the age of independent groups at the level of significance $p \leq 0.05$.

\section{Results}

Three hundred and sixty-three people (average age: 21 years, range: $18-65)$ were included in the study. $58.13 \%$ of participants were females (211) and $41.87 \%$ were males (152). The respondents were divided into three groups based on age. The first group included 290 respondents, the second 59 and the last only 14. Majority of the participants (35.0\%) lived in the countryside, $33.30 \%$ lived in the cities with $>300,000$ inhabitants, $27.0 \%$ in the towns up to 100,000 inhabitants and only $4.70 \%$ were from the towns from 100,000 to 300,000 . Results were described in Table 1.

We demonstrated statistically relationships between the respondents' sex and their knowledge of what HPV is ( $p=0.011$ ), the fact that HPV infection can be asymptomatic $(p=0.018)$, that HPV infection may be responsible for the development of oral cancer ( $p=0.032$;), there is an HPV vaccine $(p<0.001)$ and how to prevent infection $(p<$ 0.001). Overall, our female respondents were more aware.

We found statistically differences between age groups. Younger patients were more aware that HPV infection may be responsible for the development of oral cancer $(p=0.007$; in group 1), HPV infection methods $(p<0.001$; 
Table 1. Comparison of the patient survey results ( ${ }^{*}$ multiple-choice question)

\begin{tabular}{|c|c|c|c|c|c|c|c|c|c|}
\hline \multirow[t]{3}{*}{ Questions } & \multicolumn{6}{|c|}{ Age groups } & \multirow{2}{*}{\multicolumn{2}{|c|}{ All respondents }} & \multirow[t]{3}{*}{$P$-value } \\
\hline & \multicolumn{2}{|c|}{$\leq 25$} & \multicolumn{2}{|c|}{$26-40$} & \multicolumn{2}{|c|}{$>40$} & & & \\
\hline & $n$ & $\%$ & $n$ & $\%$ & $n$ & $\%$ & $n$ & $\%$ & \\
\hline \multicolumn{10}{|l|}{ HPV means: } \\
\hline Human papillomavirus & 177 & 61.03 & 38 & 64.41 & 11 & 78.57 & 226 & 62.26 & \multirow[t]{5}{*}{0.299} \\
\hline Herpes simplex virus & 32 & 11.03 & 9 & 15.25 & 1 & 7.14 & 42 & 11.57 & \\
\hline Varicella zoster virus & 2 & 0.69 & 4 & 6.78 & 0 & 0.00 & 6 & 1.65 & \\
\hline Mumps virus & 1 & 0.34 & 1 & 1.69 & 1 & 7.14 & 3 & 0.83 & \\
\hline I do not know & 78 & 26.90 & 7 & 11.86 & 1 & 7.14 & 86 & 23.69 & \\
\hline \multicolumn{10}{|l|}{ HPV infection routes*: } \\
\hline Being in one room with an infected person & 7 & 2.41 & 1 & 1.69 & 0 & 0.00 & 8 & 2.20 & \multirow[t]{11}{*}{0.280} \\
\hline Sexual contact with an infected person & 161 & 55.51 & 24 & 82.76 & 11 & 78.57 & 196 & 53.99 & \\
\hline From the mother to the foetus during delivery & 71 & 24.48 & 14 & 23.73 & 3 & 21.43 & 88 & 24.24 & \\
\hline Via placenta & 36 & 12.41 & 6 & 10.17 & 0 & 0.00 & 42 & 11.57 & \\
\hline Skin contact with an infected person & 20 & 6.90 & 13 & 22.33 & 2 & 14.29 & 35 & 9.64 & \\
\hline Breast-feeding & 23 & 7.93 & 8 & 13.55 & 0 & 0.00 & 31 & 54 & \\
\hline Contact with infected blood & 104 & 35.86 & 19 & 32.20 & 2 & 14.29 & 125 & 34.43 & \\
\hline Via food & 23 & 7.93 & 7 & 11.86 & 0 & 0.00 & 30 & 8.26 & \\
\hline Via droplets & 77 & 26.55 & 3 & 5.08 & 2 & 14.29 & 82 & 22.59 & \\
\hline Via inhalation & 0 & 0.00 & 0 & 0.00 & 0 & 0.00 & 0 & 0.00 & \\
\hline I do not know & 96 & 33.10 & 20 & 33.90 & 1 & 7.14 & 107 & 29.48 & \\
\hline \multicolumn{10}{|l|}{ HPV infection risk factors ${ }^{*}$ : } \\
\hline Smoking tobacco & 32 & 11.03 & 3 & 5.08 & 0 & 0.00 & 35 & 9.64 & \multirow[t]{12}{*}{0.212} \\
\hline Using of public toilets & 1 & 0.34 & 22 & 37.29 & 4 & 28.57 & 27 & 7.43 & \\
\hline Drinking alcohol & 10 & 3.44 & 6 & 10.17 & 0 & 0.00 & 16 & 4.41 & \\
\hline Drinking a lot of caffeine & 9 & 3.10 & 5 & 8.47 & 0 & 0.00 & 14 & 3.86 & \\
\hline Large number of sexual partners & 109 & 37.59 & 27 & 45.76 & 6 & 42.86 & 142 & 39.12 & \\
\hline Oral sex & 86 & 29.66 & 13 & 22.03 & 4 & 28.57 & 103 & 28.37 & \\
\hline Anal sex & 58 & 20.00 & 13 & 22.03 & 4 & 28.57 & 75 & 20.66 & \\
\hline Lack of regular gynaecological and dental follow-up & 84 & 28.97 & 18 & 30.51 & 3 & 21.43 & 105 & 28.93 & \\
\hline Eating unwashed vegetables and fruits & 38 & 13.10 & 8 & 13.56 & 0 & 0.00 & 46 & 12.67 & \\
\hline Numerous childbirths & 13 & 6.22 & 3 & 5.08 & 0 & 0.00 & 16 & 4.41 & \\
\hline Frequent genital infections & 70 & 24.14 & 7 & 11.86 & 2 & 14.29 & 79 & 21.76 & \\
\hline I do not know & 129 & 44.48 & 17 & 28.81 & 4 & 28.57 & 150 & 41.32 & \\
\hline \multicolumn{10}{|l|}{ HPV infection symptoms*: } \\
\hline Vesicular lesions on the lips & 46 & 15.86 & 7 & 11.86 & 4 & 28.57 & 57 & 15.70 & \multirow[t]{5}{*}{0.082} \\
\hline Warts in the oral cavity, on hands, feet, genitals & 62 & 21.38 & 22 & 37.29 & 8 & 57.14 & 92 & 25.34 & \\
\hline Enlarged cervical lymph nodes & 24 & 8.28 & 14 & 23.73 & 0 & 0.00 & 38 & 10.47 & \\
\hline Rash & 5 & 1.72 & 5 & 8.47 & 0 & 0.00 & 10 & 2.75 & \\
\hline I do not know & 97 & 33.35 & 19 & 6.55 & 4 & 28.57 & 120 & 33.06 & \\
\hline \multicolumn{10}{|l|}{ HPV infection can be asymptomatic: } \\
\hline Yes & 141 & 48.62 & 17 & 28.81 & 7 & 50.00 & 165 & 45.45 & \multirow[t]{3}{*}{0.023} \\
\hline No & 13 & 4.48 & 19 & 32.20 & 1 & 7.14 & 33 & 0.10 & \\
\hline I do not know & 136 & 46.90 & 23 & 38.98 & 6 & 42.86 & 165 & 45.45 & \\
\hline
\end{tabular}


Table 1. Cont.

\begin{tabular}{|c|c|c|c|c|c|c|c|c|c|}
\hline \multirow[t]{3}{*}{ Questions } & \multicolumn{6}{|c|}{ Age groups } & \multirow{2}{*}{\multicolumn{2}{|c|}{ All respondents }} & \multirow[t]{3}{*}{$P$-value } \\
\hline & \multicolumn{2}{|c|}{$\leq 25$} & \multicolumn{2}{|c|}{$26-40$} & \multicolumn{2}{|c|}{$>40$} & & & \\
\hline & $n$ & $\%$ & $n$ & $\%$ & $n$ & $\%$ & $n$ & $\%$ & \\
\hline \multicolumn{10}{|l|}{ HPV lesions in the oral cavity look like...* } \\
\hline White spots on the tongue, cheeks, palate & 97 & 33.45 & 16 & 21.12 & 6 & 42.86 & 119 & 32.78 & \multirow[t]{6}{*}{0.263} \\
\hline Red and white spots on the tongue, cheeks, palate & 24 & 8.27 & 13 & 22.03 & 2 & 14.29 & 39 & 10.74 & \\
\hline $\begin{array}{l}\text { Red, sore, burning papulae on the cheeks, tongue, } \\
\text { palate }\end{array}$ & 47 & 16.20 & 9 & 15.25 & 0 & 0.00 & 56 & 15.43 & \\
\hline Cauliflower eruptions on the tongue, cheeks, palate & 45 & 15.52 & 19 & 32.22 & 4 & 28.57 & 68 & 18.73 & \\
\hline Small vesicles on the inside of the lower lip & 35 & 12.07 & 15 & 25.23 & 1 & 7.14 & 51 & 14.05 & \\
\hline I do not know & 155 & 53.45 & 20 & 33.90 & 6 & 42.86 & 181 & 49.86 & \\
\hline \multicolumn{10}{|c|}{ The features of lesions caused by the HPV virus on the mucous membrane are*: } \\
\hline Soft & 34 & 11.72 & 2 & 1.35 & 2 & 14.29 & 36 & 9.92 & \multirow[t]{11}{*}{0.014} \\
\hline Painless & 26 & 8.97 & 15 & 10.14 & 0 & 0.00 & 41 & 11.29 & \\
\hline Painful & 64 & 22.07 & 30 & 20.27 & 2 & 14.29 & 96 & 26.46 & \\
\hline More often skin colour & 19 & 3.85 & 15 & 10.14 & 0 & 0.00 & 34 & 9.37 & \\
\hline Itchy & 56 & 11.34 & 21 & 14.19 & 2 & 14.29 & 79 & 21.76 & \\
\hline Not itchy & 14 & 2.83 & 13 & 8.78 & 1 & 7.14 & 28 & 7.71 & \\
\hline Cauliflower shape & 42 & 8.50 & 14 & 9.46 & 0 & 0.00 & 56 & 15.43 & \\
\hline Flat & 15 & 3.04 & 7 & 4.73 & 1 & 7.14 & 23 & 6.34 & \\
\hline Round & 36 & 7.29 & 12 & 8.11 & 1 & 7.14 & 39 & 10.74 & \\
\hline Angular & 10 & 2.02 & 1 & 0.68 & 1 & 7.14 & 12 & 3.31 & \\
\hline I do not know & 178 & 61.38 & 18 & 12.16 & 10 & 71.43 & 206 & 56.75 & \\
\hline \multicolumn{10}{|c|}{ HPV infection may be responsible for the development of oral cancer: } \\
\hline Yes & 124 & 42.76 & 9 & 15.25 & 5 & 35.71 & 138 & 38.02 & \multirow[t]{3}{*}{$<0.001$} \\
\hline No & 25 & 8.62 & 26 & 44.07 & 1 & 7.14 & 52 & 14.33 & \\
\hline I do not know & 141 & 48.62 & 24 & 40.68 & 8 & 57.14 & 173 & 47.65 & \\
\hline \multicolumn{10}{|c|}{ HPV infection may be responsible for the development of the following neoplasm: } \\
\hline Cervical cancer & 90 & 31.03 & 22 & 37.28 & 9 & 64.29 & 121 & 33.33 & \multirow[t]{9}{*}{0.485} \\
\hline Penile cancer & 26 & 8.97 & 5 & 8.47 & 5 & 37.71 & 36 & 9.92 & \\
\hline Breast cancer & 17 & 5.86 & 7 & 11.86 & 0 & 0.00 & 24 & 6.61 & \\
\hline Prostate cancer & 21 & 7.24 & 8 & 13.56 & 0 & 0.00 & 29 & 7.99 & \\
\hline $\begin{array}{l}\text { Head and neck cancer (tonsils, larynx, paranasal } \\
\text { sinuses, oral cavity) }\end{array}$ & 136 & 46.90 & 26 & 44.06 & 3 & 21.43 & 165 & 45.45 & \\
\hline Papillomatosis of the airway & 55 & 11.02 & 13 & 22.03 & 0 & 0.00 & 68 & 18.73 & \\
\hline Lung cancer & 13 & 4.48 & 6 & 10.17 & 0 & 0.00 & 19 & 5.23 & \\
\hline Progressive melanoma & 1 & 0.34 & 5 & 8.47 & 0 & 0.00 & 6 & 1.65 & \\
\hline I do not know & 140 & 48.28 & 16 & 27.12 & 4 & 28.57 & 160 & 44.08 & \\
\hline \multicolumn{10}{|l|}{ HPV infection prevention*: } \\
\hline Frequent hand washing & 46 & 15.86 & 1 & 1.69 & 2 & 14.29 & 49 & 13.50 & \multirow[t]{9}{*}{0.852} \\
\hline Using condoms & 112 & 38.62 & 19 & 32.20 & 7 & 50.00 & 138 & 38.01 & \\
\hline Loyalty to one sexual partner & 90 & 31.03 & 22 & 37.29 & 8 & 57.14 & 120 & 33.06 & \\
\hline Regular visits to the dentist & 88 & 30.34 & 0 & 0.00 & 3 & 21.43 & 91 & 25.07 & \\
\hline Personal and oral hygiene & 103 & 35.52 & 20 & 33.89 & 7 & 50.00 & 130 & 35.81 & \\
\hline Washing fruits and vegetables before eating & 49 & 16.90 & 10 & 16.95 & 0 & 0.00 & 59 & 16.25 & \\
\hline Drinking boiled water & 14 & 4.83 & 7 & 11.86 & 0 & 0.00 & 21 & 5.79 & \\
\hline Getting vaccinated & 36 & 12.41 & 9 & 15.25 & 0 & 0.00 & 45 & 12.40 & \\
\hline I do not know & 126 & 43.45 & 19 & 32.20 & 2 & 14.29 & 147 & 40.50 & \\
\hline
\end{tabular}


Table 1. Cont.

\begin{tabular}{l} 
Questions \\
\cline { 2 - 7 }
\end{tabular}

in group 2) and information about the characteristics of the lesions caused by the HPV on the mucous membrane $(p<0.001$; in group 2). Older respondents were more aware how to prevent infection ( $p=0.044$; in group 3 ).

We observed statistically relationships between the respondents' education and their knowledge of the symptoms of HPV infection ( $p<0.001$ ), the fact that HPV infection can be asymptomatic $(p=0.010)$, information about what diseases can HPV infection contribute to $(p=0.044)$, the risk factors for HPV infection $(p=0.027)$, that there is a human papillomavirus test $(p=0.011)$ and vaccine $(p=0.048)$, how to prevent infection $(p<0.001)$ and the characteristics of the mucous membrane lesions caused by the HPV $(p<0.001)$. Overall, patients with higher education had more correct responses to our survey questions.

In terms of the participants' residence (village or city/ town), we obtained statistically relationships with their answers regarding the prevention of HPV infections $(p=0.023)$. City dwellers demonstrated more knowledge on this subject.

Most respondents (62.30\%) knew what HPV was. Participants aged above 40 years old were more aware (group 1: 61.03\%; group 2: 64.41\%; group 3: 78.57\%). Almost one-third of the respondents (29.48\%) did not know the mechanism of transmission. The second group were more aware that the sexual contact with an in- fected person was the most common cause of infection (group 1: 55.51\%; group 2: 82.76\%; group 3: 78.57\%). Other infection routes mentioned included: from the mother to the foetus during delivery (group 1: $24.48 \%$; group 2: $23.73 \%$; group 3: $21.43 \%$ ) and skin contact with an infected person (group 1: 6.90\%; group 2: $22.33 \%$; group 3: $14.29 \%$ ). $58.68 \%$ of the respondents were aware about the HPV infection risk factors. Risk factors, which were the most frequently mentioned included: large number of sexual partners (group 1: $37.59 \%$; group 2: $45.76 \%$; group 3: $42.86 \%$ ), lack of regular gynaecological and dental follow-up (group 1: 28.97\%; group 2: 30.51\%; group 3: $21.43 \%$ ), oral sex (group 1: $29.66 \%$; group 2: $22.03 \%$; group 3: $28.57 \%$ ), frequent genital infections (group 1: 24.14\%; group 2: 11.86\%; group 3: $14.29 \%$ ) and anal sex (group 1: 20.00\%; group 2: 22.03\%; group 3: $28.57 \%$ ). $33.06 \%$ of the patients did not know the symptoms of HPV infection (group 1: 33.35\%; group 2: 6.55\%; group 3: $28.57 \%)$. More than half of the respondents (56.75\%, $p=0.014$ ) could not identify what the mucous membrane lesions caused by HPV looked like (group 1: 53.45\%; group 2: $33.90 \%$; group 3: 42.86\%). Participants aged up to 25 years old were more aware. $45.65 \%(p=0.023)$ of respondents did not know that HPV infection could occur in the latent form (group 1: 51.38\%; group 2: 71.79\%; group 3: 50.00\%). Participants aged above 40 years old were more aware (50.00\%). 
Almost half $(47.65 \% ; p<0.001)$ did not know that HPV infection could lead to oral cancer (group 1: 48.62\%; group 2: 40.68\%; group 3: 57.14\%). Participants aged up to 25 years old were more aware (42.76\%). The following were mentioned most frequently as other HPVrelated cancers/lesions: head and neck cancers (group 1: 46.90\%; group 2: 44.06\%; group 3: $21.43 \%$ ), cervical cancer (group 1: 31.03\%; group 2: 37.28\%; group 3: 64.29\%), papillomatosis of the airway (group 1: 11.02\%; group 2: $22.03 \%$; group 3: $0.00 \%$ ) and penile cancer (group 1: 8.97\%; group 2: 8.47\%; group 3: $37.71 \%$ ).

As many as $40.50 \%$ of our participants did not know how to protect themselves against an HPV infection. The following were mentioned most frequently as HPV infection prevention measures: using condoms (group 1: 38.62\%; group 2: 32.20\%; group 3: 50.00\%), personal and oral hygiene (group 1: $35.52 \%$; group 2: $33.89 \%$; group 3: $50.00 \%$ ) and loyalty to one sexual partner (group 1: 31.03\%; group 2: 37.29\%; group 3: 57.14\%). Participants above 40 years old were more aware (85.71\%). 68.04\% of the respondents gave wrong answer about the possibility of vaccination against HPV (group 1: 67.24\%; group 2: 77.97\%; group 3: $42.86 \%$ )

The existence of a diagnostic test detecting the presence of a virus in the body was reported only by $42 \%$ ( $p=$ 0.002 ) of respondents (group 1: $46.55 \%$; group 2: $23.73 \%$; group 3: $35.71 \%$ ). $43.5 \%$ of the respondents had no idea about treatment methods $(p<0.001)$.

\section{Discussion}

Our survey conducted among the patients revealed their insufficient knowledge about the impact of HPV infection on oral health. Only one similar study was found in the PubMed database, and this issue was mentioned in 11 other studies. The work of Lewandowski et al. concerns knowledge about the viral infections and the impact of the risk of sexual behaviour on the occurrence of oral cancer [22]. That particular study involved 196 students who were 19-25 years of age and stated that HPV infection was primarily associated with squamous cell carcinoma of the cervix. Contrarily to our study, Lewandowski et al. had respondents just in one age group, up to 25 years. The role of HPV virus as a factor in the development of benign and malignant lesions was indicated by $59.7 \%$ of the respondents of Lewandowski et al., and by $61 \%$ of our respondents. The relationship between HPV infection and the occurrence of oral cancer was noted by $40.3 \%$ of the students interviewed by Lewandowski et al. and by $42.76 \%$ of our patients. In our study, oral sex, as a risk factor for HPV infection, was reported by $13.46 \%$ of our respondents, and by $34.7 \%$ of the respondents in the study by Lewandowski et al. The availability of the HPV vaccine as an element of the prevention of oral cancer is reported by $50.5 \%$ of the surveyed students, and among our patients this percentage is only $38.3 \%$ [22].
A study by Osazuwa-Peters et al. showed that $36 \%$ of respondents knew that HPV could contribute to oral cancer [23]. In addition, participants of the study indicated that HPV was mainly associated with cervical cancer. We obtained similar results. Pokharel et al. proved that 2 out of 3 respondents did not realize the relationship between oral sex and oral cancer [24]. Wroński et al. showed that patients were not aware of the relationship between oral cancer and oral sex or a large number of sexual partners [25]. In our study, the relationship between oral cancer and oral sex was identified by $13.46 \%$ of patients in the group up to 25 years of age, and $9.15 \%$ in the group of $26-40$, and $14.81 \%$ over 40 years of age. In turn, the relationships between a large number of sexual partners were indicated by $17.06 \%, 19.15 \%$ and $22.22 \%$ of respondents respectively. In the work by Taberna et al., $40 \%$ of respondents indicated that HPV vaccination was important in the prevention of oral cancer [26].

There is a need to educate patients about the relationship between HPV infection and oral cancer, which was noticed by Dood et al. and Daley et al. [27, 28]. The respondents emphasized the role of medical personnel in expanding knowledge about HPV-positive oral cancer. According to interviewees, the information provided by medical personnel was more reliable than information from internet portals or the media.

The study by Bakr et al. conducted among students of dentistry and dental patients showed that their knowledge about the symptoms and risk factors (including HPV infection) of oral cancer was relatively low [29]. In the work of Formosa et al., 23\% of respondents reported a connection between HPV infection and the occurrence of oral cancer [30]. In our study, it was 38\% of the respondents. The results of a study conducted by Kram et al. among the parents of paediatric ward patients showed that $51.3 \%$ of respondents were aware of a vaccine against HPV and showed a desire to obtain additional information on vaccinations [31]. In our sample, $38.9 \%$ of patients knew about the availability of a vaccine against HPV. In addition, Kram et al. demonstrated that only $19.6 \%$ of respondents were aware of HPV infection as a risk factor for squamous cell carcinoma of the head and neck. Gichki et al. focused on issues related to HPV infection, and $53.1 \%$ of their respondents were aware that the HPV infection was influenced by sexual contact, however they did not know that HPV could be transmitted through mucous membranes and through the infected mother to the foetus [32]. In turn, as many as $59.4 \%$ of respondents did not realize that HPV infection had a significant impact on the development of potentially malignant disorders as well as malignant neoplasms of the head and neck. McBride et al. showed significant statistical differences between gender and knowledge about HPV infection and vaccines. Women had better general knowledge about HPV, and men about vaccination. In addition, the relationship between general knowledge and education, white race and higher earnings was 
demonstrated. Negative correlation was found in people over 65, among black and Asian races. Most participants (> 70\%) knew that HPV might cause cervical cancer, but less people (14.9\% to $31.5 \%)$ knew about the relationship between HPV and cancers of other parts of the body [33].

\section{Conclusions}

Our study suggests that patients' awareness of the influence of HPV infections on oral health is limited. There is a need to educate patients about the risk factors for HPV infection and prevention methods, including the possibility of vaccinating themselves against HPV.

\section{Conflict of interest}

The authors declare no conflict of interest.

\section{References}

1. Ganly I, Yang L, Giese RA, et al. Periodontal pathogens are a risk factor of oral cavity squamous cell carcinoma, independent of tobacco and alcohol and human papillomavirus. Int J Cancer 2019; 145: 775-84.

2. Orosco RK, Kedarisetty S, Hecht AS, et al. Predictors of high-risk and low-risk oral HPV infection in the United States. Laryngoscope 2016; 126: 1365-72.

3. Zur Hausen $\mathrm{H}$. The search for infectious causes of human cancers: where and why. Virology 2009; 392: 1-10.

4. de Abreu PM, Có ACG, Azevedo PL, et al. Frequency of HPV in oral cavity squamous cell carcinoma. BMC Cancer 2018; 18: 324.

5. Nguyen HP, McNiece KL, Duong AA, et al. Human papillomavirus infection of the oral mucosa and upper respiratory tract. Curr Probl Dermatol 2014; 45: 132-53.

6. Stojanov IJ, Woo SB. Human papillomavirus and Epstein-Barr virus associated conditions of the oral mucosa. Semin Diagn Pathol 2015; 32: 3-11.

7. Ünal E, Gönül M, Çakmak S, et al. Serological test results of sexually transmitted diseases in patients with condyloma acuminata. Adv Dermatol Allergol 2015; 32: 286-9.

8. Yete S, D'Souza W, Saranath D. High-risk human papillomavirus in oral cancer: clinical implication. Oncology 2018; 94: 133-41.

9. Ozaydin-Yavuz G, Bilgili SG, Guducuoglu H, et al. Determinants of hgh-risk human papillomavirus infection in anogenital warts. Adv Dermatol Allergol 2019; 36: 76-81.

10. Kim SM. Human papilloma virus in oral cancer.J Korean Assoc Oral Maxillofac Surg 2016; 42: 327-36.

11. van Houten VM, Snijders PJ, van den Brekel MW, et al. Biological evidence that human papillomaviruses are etiologically involved in a subgroup of head and neck squamous cell carcinomas. Int J Cancer 2001; 93: 232-5.

12. Gillison ML, Broutian T, Pickard RK, et al. Prevalence of oral HPV infection in the United States, 2009-2010. JAMA 2012; 307: 693-703.

13. Dunne EF, Unger ER, Sternberg M, et al. Prevalence of HPV infection among females in the United States. JAMA 2007; 297: 813-9.

14. Huebbers CU, Akguel B. HPV and cancer of the oral cavity. Virulence 2015; 6: 244-8.

15. Klozar J, Kratochvil V, Salakova M, et al. HPV status and regional metastasis in the prognosis of oral and oropharyngeal cancer. Eur Arch Otorhinolaryngol 2008; 265 Suppl 1: S75-82.
16. Mellin $\mathrm{H}$, Friesland $\mathrm{S}$, Lewensohn R, et al. Human papillomavirus (HPV) DNA in tonsillar cancer: clinical correlates, risk of relapse, and survival. Int J Cancer 2000; 89: 300-4.

17. Prawdzic Seńkowska A, Kiczmer P, Strzelczyk JK, et al. Impact of HPV infection on gene expression and methylation in oral cancer patients. J Med Microbiol 2019; 68: 440-5.

18. Chaturvedi AK, Engels EA, Anderson WF, et al. Incidence trends for human papillomavirus-related and -unrelated oral squamous cell carcinomas in the United States. J Clin Oncol 2008; 26: 612-9.

19. Sudhakaran A, Hallikeri K, Babu B. p16 as an independent marker for detection of high-risk HPV in oral submucous fibrosis and oral squamous cell carcinoma. Indian J Pathol Microbiol 2019; 62: 523-8.

20. Koslabova E, Hamsikova E, Salakova M, et al. Markers of HPV infection and survival in patients with head and neck tumors. Int J Cancer 2013; 133: 1832-9.

21. Orrù G, Mameli A, Demontis C, et al. Oral human papilloma virus infection: an overview of clinical-laboratory diagnosis and treatment. Eur Rev Med Pharmacol Sci 2019; 23: 8148-57.

22. Lewandowski B, Czenczek-Lewandowka E, Pakla P, et al. Awareness of Polish undergraduate and graduate students regarding the impact of viral infections and high-risk sexual behaviors on the occurrence of oral cancer. Medicine 2018; 97: e12846.

23. Osazuwa-Peters N, Adjei Boakye E, Mohammed KA, et al. Not just a woman's business! Understanding men and women's knowledge of HPV, the HPV vaccine, and HPV-associated cancers. Prev Med 2017; 99: 299-304.

24. Pokharel M, Shrestha I, Dhakal A, et al. Awareness and knowledge of oral cancer among medical students in Kathmandu University School of Medical Sciences. Kathmandu Univ Med J 2017; 15: 75-7.

25. Wroński K, Bocian R, Depta A, et al. What patients know about the etiology of oral carcinoma resulting from oral sex. Gin Prak 2010; 2: 12-6.

26. Taberna M, Mena M, Pavón MA, et al. Human papillomavirusrelated oropharyngeal cancer. Ann Oncol 2017; 28: 2386-98.

27. Dood RH, Forster AS, Waller J, et al. Discussing HPV with oropharyngeal cancer patients: a cross-sectional survey of attitudes in health professionals. Oral Oncol 2017; 68: 67-73.

28. Daley EM, Thompson EL, Vamos CA, et al. HPV-related knowledge among dentists and dental hygienists. J Cancer Educ 2018; 33: 901-6.

29. Bakr MM, Skerman E, Khan U, et al. Oral cancer: an evaluation of knowledge and awareness in undergraduate dental students and the general public. Oral Health Prev Dent 2016; 14: 403-11.

30. Formosa J, Jenner R, Nguyen-Thi MD, et al. Awareness and knowledge of oral cancer and potentially malignant oral disorders among dental patients in Far North Queensland, Australia. Asian Pac J Cancer Prev 2015; 16: 4429-34.

31. Kram YA, Schmidt TH, Saghezchi S, et al. Attitudes toward human papilloma virus vaccination and head and neck cancer prevention in a Diverse, Urban Population. Otolaryngol Head Neck Surg 2015; 153: 538-43.

32. Gichki AS, Buajeeb W, Doungudomdacha S, et al. Knowledge of human papillomavirus and its association with head and neck benign and malignant lesions in a group of dental patients in Pakistan. Asian Pac J Cancer Prev 2015; 16: 1581-5.

33. McBride KR, Singh S. Predictors of adults' knowledge and awareness of HPV, HPV-associated cancers, and the HPV vaccine: implications for health education. Health educ Behav 2018; 45: 68-76. 


\section{Appendix 1. The questionnaire form}

\section{Assessment of awereness of human papillomavirus infection on oral cavity among patients}

\section{Sociodemographic questions:}

1) Gender:
a) Male
b) Female

2) Age....

3) Education:
a) Primary education
b) Secondary education
c) Higher education
d) Vocational education

4) Place of residence:
a) Village
b) A city of up to 100,000 inhabitants
c) A city of up to 300,000 inhabitants
d) A city with over 300,000 inhabitants

\section{HPV-specific questions:}

5) HPV means:
a) Human papillomavirus
b) Herpes simplex virus
c) Varicella zoster virus
d) Mumps virus
e) I do not know

6) HPV infection routes*:

a) Being in one room with infection person

b) Sexual contact with infected person

c) From the mother to the fetus during delivery

d) Via placenta

e) Skin contact with infected person

f) Breast-feeding

g) Contact with infected blood

h) Via food

i) Via droplets

j) Via inhalation

k) I do not know

7. HPV infection risk factors*:
a) Smoking tobacco
b) Using of public toilets
c) Drinking alcohol
d) Drinking a lot of caffeine
e) Large number of sexual partners
f) Oral sex
g) Anal sex
h) Lack of regular gynaecological and dental follow- up
i) Eating unwashed vegetables and fruits
j) Numerous childbirths

k) Frequent genital infections

l) I do not know

8. HPV infection symptoms*:
a) Vesicular lesions on the lips
b) Warts in the oral cavity, on hands, feet, genitals
c) Enlarged cervical lymph nodes
d) Rush
e) I do not know

9. HPV infection can be asymptomatic:
a) Yes
b) No
c) I do not know

10. HPV lesions in the oral cavity look like...*:
a) White spots on the tongue, cheks, palate
b) Red and white spots on the tongue, cheeks, palate
c) Red, sore, burning papulae on the cheeks, palate
d) Cauliflower eruptions on the tomgue, cheeks, pal- ate
e) Small vesicles on the inside of the lower lip
f) I do not know

11. The features of lesions caused by the HPV virus on the mucous membrane are*:
a) Soft
b) Painless
c) Painful
d) More often skin colour
e) Itchy
f) Not itchy
g) Cauliflower shapes
h) Flat
i) Round
j) Angular
k) I do not know

12. HPV infection may be responsible for the development of oral cancer:
a) Yes
b) No
c) I do not know

13. HPV infection may be responsible for the development of the following neoplasm*:
a) Cervical cancer
b) Penile cancer
c) Breast cancer
d) Prostate cancer
e) Head and neck cancer (tonsils, larynx, paranasal sinuses, oral cavity)



f) Papilomatosis of the airway
g) Lung cancer
h) Progressive melanoma
i) I do not know

14. HPV infection prevention*:
a) Frequent hand washing
b) Using condoms
c) Loyalty to one sexual partner
d) Regular visists to the dentist
e) Personal and oral hygiene
f) Washing fruits and vegetables before eating
g) Drinking boiled water
h) Getting vaccinated
i) I do not know

15. Is there an HPV vaccine?

a) Yes, but it is not obligatory

b) Yes, and it is an obligatory vaccination (in Poland) c) $\mathrm{No}$

d) I do not know

16. Is there an HPV test?
a) Yes
b) No
c) I do not know

17. HPV infection treatment*:

a) Antibiotics

b) Antiviral drugs

c) Surgery

d) Infection is incurable, but the skin lesions can be removed

e) laser therapy

f) Burning off

g) Cryotherapy

h) I do not know

*Multiple-answer question - a minimum of three responses are correct. 